\title{
TWO CASES OF POSTURAL HYPOTENSION SHOWING A DE- FICIENCY IN RELEASE OF NOR-EPINEPHRINE AND EPINEPHRINE
}

\author{
By ROLF LUFT AND ULF S. VON EULER \\ (From the Department of Endocrinology of Serafimerlasarettet, and the Department of Physi- \\ ology, Karolinska Institutet, Stockholm, Sweden)
}

(Submitted for publication April 6, 1953; accepted July 23, 1953)

Of the two forms of orthostatic hypotension, one, the arterial orthostatic anemia or hypotonic regulatory disturbance (1), is characterized by an increase in the pulse rate and a fall of the systolic blood pressure, with or without a rise in the diastolic pressure, upon change from the recumbent to the erect posture. These circulatory reactions are due to an increased activity of the sympathetic nervous system, which normally compensates for the hydrostatic displacement of blood due to the changes in position. In the second form, the postural hypotension or hypodynamic regulatory disturbance, this reaction of the sympathetic system to changes in posture is absent. The result is a momentary fall of the systolic as well as the diastolic blood pressure during a change from the recumbent to the erect posture, the pulse rate being maintained at a constant level (Figure 1).

Postural hypotension was described for the first time in 1925 by Bradbury and Eggleston (2). It is a rather rare condition, of which Springarn and Hitzig (3), in 1942, found only 50 cases described in the literature. It is supposed to be due to organic lesions in the brain stem or spinal cord, following encephalitis, encephalomalacia and tumors, tabes dorsalis, syringomyelia and hematomyelia (4-6). A similar condition may also occur after extensive sympathectomies (7-9). Hammarström and Lindgren (10) made histological studies of the central nervous system in a case of postural hypotension and found lesions located in the right internal capsule, the cerebellum, the occipital lobes, and the cortex of the lateral parts of the hemispheres of the cerebrum.

In the present study of two cases of postural hypotension, the authors determined the daily urinary excretion of the catechol amines, epinephrine and nor-epinephrine. The urinary output of epinephrine after intravenous administration of insulin, which increases the output by ten-fold in healthy subjects (11), was also studied. In one of the cases, the urinary excretion of catechol amines was followed during an intravenous infusion of norepinephrine, as well as after a subcutaneous injection of histamine.

\section{EXPERIMENTAL}

\section{Methods}

The catechol amines in urine were determined according to the methods of Euler (12), and Euler and Hellner (13). The procedure consists, in principle, of selective adsorption of the catechol amines in the urine on aluminum hydroxide after acid hydrolysis. After elution, the adsorbed catechols are tested on the cat's blood pressure and on the hen's rectal caecum, permitting estimation of epinephrine and nor-epinephrine separately.

Insulin tolerance test. The patients were kept fasting over-night and given $0.1 \mathrm{I}$.U. of insulin per $\mathrm{Kg}$. body weight intravenously at 8 A.M. Samples of capillary blood were taken $10,20,30,45,60,75,90,120,150$, and 180 minutes after the injection. The blood pressures and pulse rates were determined at regular intervals. The patients' reports on hypoglycemic symptoms were noted. The urine was collected from a period of approximately two hours before (control) and three hours after the injection of insulin.

Intravenous infusion of nor-epinephrine. The ability of intravenously infused nor-epinephrine to pass through the kidneys into the urine was studied in one of the present cases (Case 1). In each of two experiments, $400 \mu \mathrm{g}$. of dl-nor-epinephrine (approximately equivalent to $200 \mu \mathrm{g}$. of the levo-compound) was administered intravenously as a constant infusion during 50 to 90 minutes. The urine was collected for two hours before (control), as well as two hours after, the start of the infusion. Epinephrine and nor-epinephrine were determined according to the methods described above. Previous experiments by Euler and Luft (14) have shown that 1.5 to 3.3 per cent of the infused amounts of nor-epinephrine are excreted during the time of infusion. Similar results were obtained by Goldenberg (15).

Effect of histamine on the excretion of catechol amines. A preliminary study was made of the effect of histamine in releasing epinephrine from the chromaffine cells (see Dale, [16]). A dose of $0.5 \mathrm{mg}$. of histamine dihydrochloride 
was given subcutaneously to ten healthy subjects and twice to Case 1 of the present study. The urine was collected for two hours before (control) and three hours after the injection and submitted for analyses of epinephrine and nor-epinephrine.

\section{Case Reports}

Two cases were studied. They have been reported earlier by Luft and Sjögren (17).

Case 1. Unmarried man, 47 years old. He had rheumatoid arthritis in 1913. The first symptoms of his present illness appeared in 1938 and consisted of tiredness and dizziness, most pronounced in the mornings and during warm weather. He lost the ability to perspire. The libido disappeared. He often fainted, especially when he had to stand upright for some time. When examined in 1946 he had been almost completely incapacitated for the last year. Body weight, $57 \mathrm{Kg}$., body length $176 \mathrm{~cm}$. No abnormal pigmentations; normal findings on neurological examination. No change in pulse rate or blood pressure was obtained when pressure was applied to the carotid sinus. Physical examination of the testicles and the prostate gland was normal. There were no clinical signs of adrenal cortical insufficiency. BMR +1 per cent. Normal findings on liver puncture. Glomerular filtration rate (inulin) $99 \mathrm{ml}$. per minute, renal plasma flow (diodrast), $399 \mathrm{ml}$. per minute. Water load test $(1000 \mathrm{ml}$.) showed a normal ability to dilute, concentrate and excrete. Cutler's test was normal. X-ray examinations of heart, lungs, kidneys, adrenal regions, stomach, intestines, and sella turcica were normal. Wasserman's reaction was negative. No orthostatic phenomena were observed on electrocardiogram.

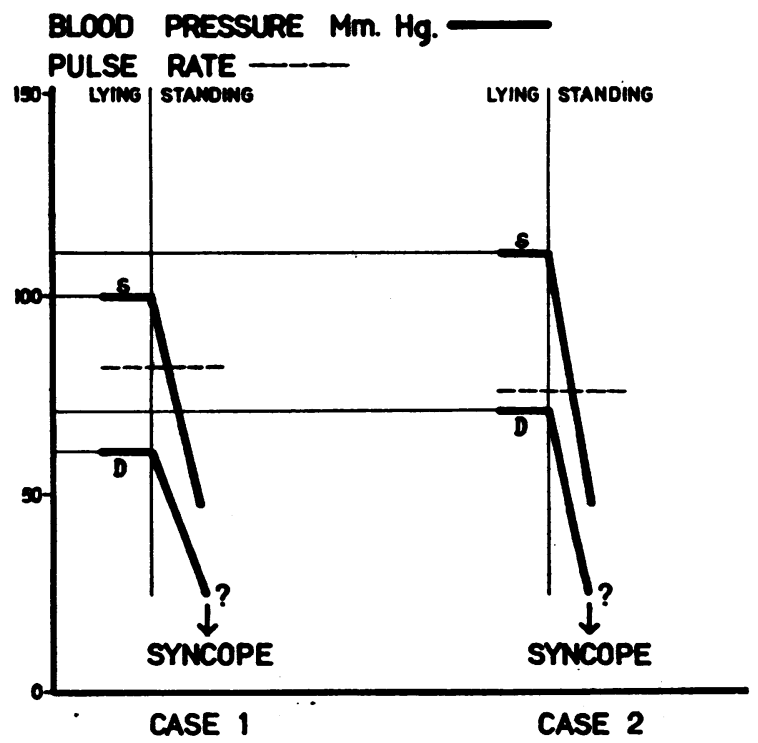

Fig. 1. Change in Systolic and Diastolic Blood Pressure during Orthostatic Tests in Two Cases of Postural Hypotension
Blood pressure (Figure 1) : in the morning at rest 90 $120 / 50-70 \mathrm{~mm}$. $\mathrm{Hg}$; when standing up an immediate fall of the systolic pressure to $50-60 \mathrm{~mm}$. $\mathrm{Hg}$ was observed, while the diastolic pressure fell below $30 \mathrm{~mm}$. $\mathrm{Hg}$ and could not be accurately measured. The pulse rate remained unchanged. After the subcutaneous administration of 0.5 mg. of ergotamine tartrate the pressure was $175 / 125 \mathrm{~mm}$. $\mathrm{Hg}$ while recumbent, and $100 / 60 \mathrm{~mm}$. $\mathrm{Hg}$ when standing. A similar effect was obtained with epinephrine and ephedrin.

After subcutaneous administration of $1 \mathrm{mg}$. of dl-norepinephrine, the blood pressure in erect posture was kept normal for several minutes.

Case 2. Married woman, born 1895. Menopause in 1946. Symptoms of present illness date from 1946 and consist of extreme fatigue, gain in weight, decreased tolerance to cold, constipation and loss of the ability to perspire. Since 1947 she had syncopal attacks which have increased in frequency. Since 1948 she fainted when she tried to walk for more than a few steps. The secondary hair growth was normal, and she had no abnormal pigmentations. There were no clinical signs of adrenal cortical insufficiency or hypothyroidism. Normal findings were present on neurological examination. Electrocardiogram at rest was normal, and there were no orthostatic changes in erect posture. BMR :-11 per cent. Glomerular filtration rate (inulin) was $80 \mathrm{ml}$. per minute and renal plasma flow (diodrast) $440 \mathrm{ml}$. per minute. X-ray examinations of sella turcica, heart, lungs, intestines and stomach were normal; the gallbladder contained several stones.

In 1951, the patient had severe hematuria, and later the same year was operated on for a hypernephroma of the right kidney. No metastases were found at the operation or afterwards.

Blood pressure (Figure 1) in the morning at rest was $100-130 / 60-85 \mathrm{~mm}$. $\mathrm{Hg}$. On changing to the erect posture there was an immediate fall of the systolic pressure to 40-50 $\mathrm{mm}$. $\mathrm{Hg}$, while the diastolic pressure fell below $30 \mathrm{~mm} . \mathrm{Hg}$. The pulse rate remained unchanged. After administration of $0.5 \mathrm{mg}$. of ergotamine tartrate, subcutaneously, the reclining pressure was $180 / 115$ while the standing pressure was $75 / 55 \mathrm{~mm}$. $\mathrm{Hg}$.

When one mg. of dl-nor-epinephrine was administered subcutaneously, the blood pressure with the patient in the erect posture remained normal for several minutes. When one $\mathrm{mg}$. was given in a suspension in oil with ascorbic acid as a stabilizer, it was kept normal or even elevated for about one hour. However, palpitations, oppression, and a feeling of apprehension made this treatment less attractive.

\section{RESULTS}

\section{Resting secretion}

The daily excretion of epinephrine and norepinephrine in our two cases of postural hypotension as well as in healthy subjects are given in Table I. Table II shows the values of excretion 
TABLE I

Daily urinary excredion of opinepherine and nor-epinephrine in two cases of postural hypotension

\begin{tabular}{cccc}
\hline \hline Case & $\begin{array}{c}\text { Epinephrine } \\
\text { in urine } \\
\text { no./24 hours }\end{array}$ & $\begin{array}{c}\text { Nor-epinephrine } \\
\text { in urine } \\
\text { ms./24 hours }\end{array}$ & $\begin{array}{c}\text { Epinephrine } \\
\text { in per cent } \\
\text { of total } \\
\text { catechols } \\
\text { in urine }\end{array}$ \\
\hline 1 & 2.0 & 13.0 & 13 \\
2 & 2.8 & 5.8 & 33 \\
& 1.2 & 3.0 & 28 \\
& 0.92 & 5.3 & 14 \\
& 0.80 & 3.6 & 18 \\
Healthy & 0.62 & 2.7 & 19 \\
subjects & 0.93 & 4.2 & 18 \\
\hline
\end{tabular}

figures during a control period before administration of insulin. The control figures earlier reported by Euler and Luft (11) and included in Table II are somewhat high since these subjects arrived at the laboratory in the morning which involved a certain degree of activity. In hospitalized patients the control excretion figures should be about $2 \mathrm{~m} \mu \mathrm{g}$. per minute of epinephrine and 20 $\mathrm{m} \mu \mathrm{g}$. per minute of nor-epinephrine.

As seen in Table I, the catechol amine output in the cases of postural hypotension was low when compared with the normal values. This holds true especially for nor-epinephrine. The excretion of epinephrine during the control period (before the injection of insulin), 0.8 to $2.8 \mathrm{~m} \mu \mathrm{g}$. per minute, and 0.62 to $2.8 \mu \mathrm{g}$. per 24 hours, was low but possibly within the normal range for an individual at rest. The excretion of nor-epinephrine was, however, only 2.0 to $7.3 \mathrm{~m} \mu \mathrm{g}$. per minute during the control period, and 2.7 to $13 \mu \mathrm{g}$. per 24 hours.

\section{Insulin test}

While insulin in normal subjects increased the epinephrine output by about $50 \mathrm{~m} \mu \mathrm{g}$. per minute (11), it did not change the excretion of catechols significantly in the two present cases. The largest increase of epinephrine, from a control value of 1.3 to $7.7 \mathrm{~m} \mu \mathrm{g}$. per minute, is of doubtful significance.

The pulse rate was unchanged throughout the tolerance test in three out of four studies. The blood pressure showed a continuous fall during the initial 60 to 90 minutes after the insulin injection. The initial values and the lowest values obtained are recorded in Table II. In all instances the blood pressure then rose to the initial level.

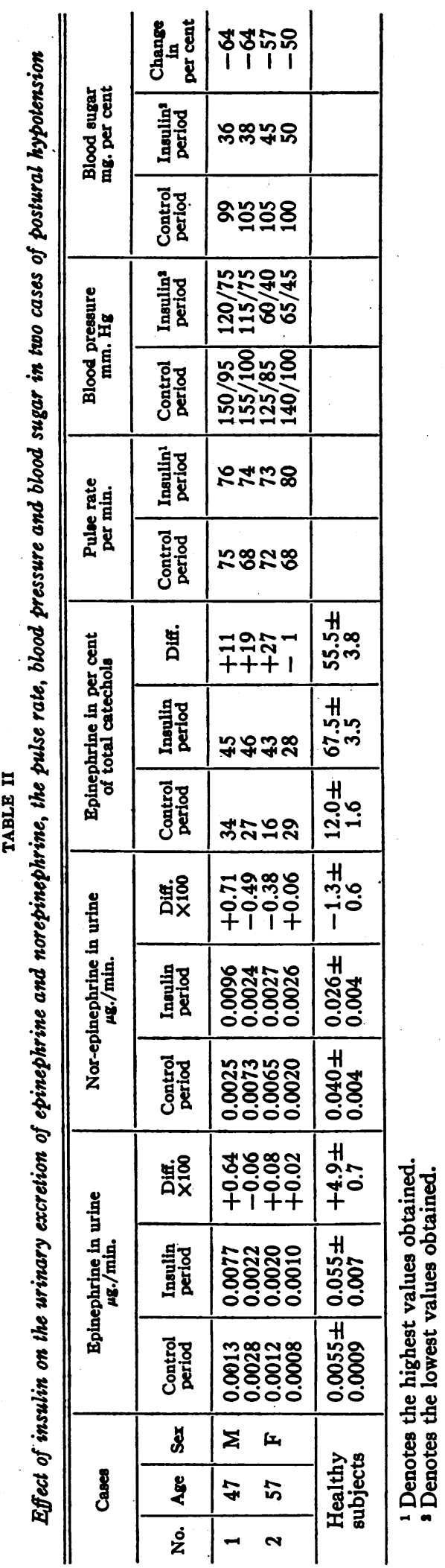


In healthy subjects the insulin hypoglycemia is accompanied by an increase of the systolic and a decrease of the diastolic blood pressure as well as an accelerated pulse rate $(11,18)$. These and other changes would be best explained by an increased secretion of epinephrine $(11,19)$. The absence of circulatory signs in the two cases of postural hypotension after insulin is in accord with the lack of increase in epinephrine excretion observed in the present study.

The decrease in blood sugar after insulin administration was pronounced in these cases. It returned to the initial level except for experiment 2 (case 1), where glucose had to be given after 40 minutes to get the patient out of a comatose state. Despite this, the blood sugar did not return to the initial level for the remainder of the period.

The subjective reaction to insulin which appeared after some 10 to 15 minutes, mainly consisted of sleepiness and drowsiness. During a large part of the insulin period the patients were asleep and woke up only when the blood samples were taken. In three insulin tolerance tests the symptoms gradually disappeared during the last hour. In study 2 , the patient went into coma with convulsions (see above). In no instance did there appear sweating, palpitations, or an agitated state, mostly observed in healthy subjects during an insulin tolerance test. In the cases of postural hypotension, there was more of a "silent fading out."

During the infusion of $400 \mu \mathrm{g}$. of dl-nor-epinephrine to case $1,0.6$ and 1.0 per cent, respectively, were excreted in the urine in two studies, which may be regarded as approximately normal (14). The amount of nor-epinephrine excreted increased from 2.5 to 14 and in the second study from 3.4 to $27 \mathrm{~m} \mu \mathrm{g}$. per minute. At the same time epinephrine increased from the control values of 2 and 0.5 to 9 and $5 \mathrm{~m} \mu \mathrm{g}$. per minute, respectively.

In a preliminary study the injection of $0.5 \mathrm{mg}$. of histamine dihydrochloride subcutaneously in ten healthy subjects evoked an increase in the excretion of epinephrine from a mean control value of $2.3 \mathrm{~m} \mu \mathrm{g}$. per minute to 7.5 during the first and 15 during the second hour after the injection. The increase in the excretion was thus 5.2 and $13 \mathrm{~m} \mu \mathrm{g}$. per minute. All subjects demonstrated a marked reaction with flushing of the face and complained of headache for some minutes up to one hour. When the same histamine dose was given to case
1 , the patient did not show any such reaction at all. The excretion of epinephrine showed a hardly demonstrable increase, from a control value of 0.3 to 0.6 and $0.9 \mathrm{~m} \mu \mathrm{g}$. per minute during the first and second hour after the injection, which means an increase of 0.3 and $0.6 \mathrm{~m} \mu \mathrm{g}$. per minute, only.

The spontaneous excretion of nor-epinephrine was not significantly altered by histamine.

\section{DISCUSSION}

The diagnosis of postural hypotension in the present two cases seems to the authors to be beyond question. They demonstrated all the characteristic symptoms of the disease and did not reveal any signs of other disturbances in the circulatory system or in the endocrine glands.

The daily excretion of epinephrine and norepinephrine was low in both cases, which may well be connected with the inability of the sympathetic nervous system to react to changes in posture. In this connection it should be noted that subcutaneous administration of nor-epinephrine relieved the patients of all signs of hypotension.

In general, a decreased excretion of catechol amines may be due to: a) An inability of catechol amines released to pass through the kidneys into the urine; b) an inability of the adrenergic nerve endings and the chromaffine cells to react to stimuli and to produce or release the hormones; and c) an inability of the centers to react to physiological stimuli and to send impulses leading to a release of catechol amines from the adrenergic nerve endings or the chromaffine cells.

As to the first point, intravenous administration of nor-epinephrine to one of our cases gave rise to an increase in the excretion of nor-epinephrine that was only a little below the increase obtained under similar conditions in healthy subjects (14). This shows the intact ability of the kidneys to excrete circulating nor-epinephrine with the urine.

As to the second point, the studies with histamine have demonstrated a decreased ability of the adrenal medulla to release epinephrine on direct stimulation. Since about 80 per cent of the total catechols of the adrenal medulla is epinephrine and only 20 per cent nor-epinephrine (20), the effect of histamine will be reflected mainly on the excretion of epinephrine. Whether the lack of histamine response is due to lack of medullary epinephrine or other causes cannot be decided. 
The failure of insulin hypoglycemia to evoke an increased secretion of epinephrine in the case studied might then be explained by an inability of the adrenal medulla to produce catechol amines, although functional damage to the regulating centers or blocking of the efferent sympathetic pathways has to be considered as a cause. The occurrence of injuries in the central nervous system in cases of postural hypotension suggests the latter possibility.

Clearly the low and physiologically inadequate secretion of nor-epinephrine from the adrenergic nerve endings could be explained along the same lines, i.e., failing production or absence of secretory impulses. Catechol amine analyses of organs might give some information on this point.

A decreased ability of the adrenergic nerve endings to form nor-epinephrine bears certain analogies to the conditions in myasthenia gravis, where the motor nerves apparently do not produce adequate amounts of acetylcholine.

\section{SUMMARY}

In two typical cases of postural hypotension, the spontaneous urinary excretion of nor-epinephrine was markedly decreased.

The normally occurring strong increase in the excretion of epinephrine after intravenous administration of insulin was lacking in these patients. The pulse rate and blood pressure did not show the changes, during insulin hypoglycemia, typical of the secondary hyperadrenalinemia in normal subjects. The hypoglycemic symptoms were different from those observed in healthy subjects after insulin administration.

Infused nor-epinephrine was excreted in a normal way when tested in one of the patients. A complete refractoriness to histamine was noted, both as regards subjective signs and with regard to the normally occurring increase in epinephrine excretion in the urine.

The possible mechanisms of the diminished catechol amine excretion in these cases is discussed.

\section{REFERENCES}

1. Schellong, F., Störung der Kreislaufregulation, ein neues Symptom bei Insuffizienz des Hypophysenvorderlappens. Klin. Wchnschr., 1931, 10, 100.

2. Bradbury, S., and Eggleston, C., Postural hypotension, a report of three cases. Am. Heart J., 1925, 1, 73.
3. Springarn, C. L., and Hitzig, W. M., Orthostatic circulatory insufficiency; its occurrence in tabes dorsalis and Addison's disease. Arch. Int. Med., 1942, 69, 23.

4. Stead, E. A., Jr., and Ebert, R. V., Postural hypotension; A disease of the sympathetic nervous system. Arch. Int. Med., 1941, 67, 546.

5. Ellis, L. B., and Haynes, F. W., Postural hypotension, with particular reference to its occurrence in disease of the central nervous system. Arch. Int. Med., 1936, 58, 773.

6. Nylin, G., and Levander, M., Studies on the circulation with the aid of tagged erythrocytes in a case of orthostatic hypotension (asympathicotonic hypotension). Ann. Int. Med., 1948, 28, 723.

7. Roth, G. M., Postural effects on blood pressure following interruption of vasomotor nerves of man. Am. Heart J., 1937, 14, 87.

8. MacLean, A. R., and Allen, E. V., Orthostatic hypotension and orthostatic tachycardia; treatment with the "head-up" bed. J. A. M. A., 1940, 115, 2162.

9. Hammarström, S., Orthostatic hypotension after sympathectomy in hypertensives-the possible key to the beneficial effect of the operation. Acta med. Scandinav., 1942, 110, 126.

10. Hammarström, S., and Lindgren, §. G. H., Postural hypotension in a patient with multiple encephalomalacias. Acta med. Scandinav., 1942, 111, 537.

11. Euler, U. S. von, and Luft, R., Effect of insulin on urinary excretion of adrenalin and noradrenalin; Studies in ten healthy subjects and in six cases of acromegaly. Metabolism, 1952, 1, 528.

12. Euler, U. S. von, The distribution of sympathin $\mathrm{N}$ and sympathin $A$ in spleen and splenic nerves of cattle. Acta physiol. Scandinav., 1949, 19, 207.

13. Euler, U. S. von, and Hellner, S., Excretion of noradrenaline, adrenaline, and hydroxytyramine in urine. Acta physiol. Scandinav., 1951, 22, 161.

14. Euler, U. S. von, and Luft, R., Noradrenaline output in urine after infusion in man. Brit. J. Pharmacol., 1951, 6, 286.

15. Goldenberg, M., Adrenal medullary function. Am. J. Med., 1951, 10, 627.

16. Dale, H. H., Conditions which are conducive to the production of shock by histamine. Brit. J. Exper. Path., 1920, 1, 103.

17. Luft, R., and Sjögren, B., The effect of desoxycorticosterone acetate (DCA) and sodium chloride on blood pressure in postural hypotension and arterial orthostatic anemia. Acta endocrinol., 1949, 2, 287.

18. Ernstene, A. C., Riseman, J. E. F., Stern, B., and Alexander, B., The mechanism of the circulatory changes accompanying insulin hypoglycemia. Am. J. Physiol., 1935, 111, 440.

19. Dury, A., The effect of epinephrine and insulin on the plasma potassium level. Endocrinology, 1951, 49, 663.

20. Hellström, J., Euler, U. S. von, Franksson, C., and Gemzell, C. A., Binjureexstirpation vid prostatacancer. Nord. med., 1952, 48, 1119. 